\title{
Northeast Tibetan Crustal Structure from INDEPTH IV Controlled- Source Seismic Data
}

\author{
Marianne Karplus ${ }^{1}$, Simon Klemperer, ${ }^{1}$, Z Zhao Wenjin², Wu Zhenhan², Shi Danian², Su Heping ${ }^{2}$, \\ Larry Brown ${ }^{3}$, Chen Chen ${ }^{3}$, Jim Mechie ${ }^{4}$, Rainer Kind ${ }^{4}$, Fred Tilmann ${ }^{5}$, Yizhaq Makovsky ${ }^{6}$, Rolf \\ Meissner ${ }^{7}$ and INDEPTH Team
}

1 Department of Geophysics, Stanford University, CA 94305-2215, USA

2 Chinese Academy of Geological Sciences (CAGS), Beijing 100037, CHINA

3 Department of Earth and Atmospheric Sciences, Cornell University, NY 14853, USA

${ }^{4}$ GeoForschungsZentrum (GFZ), Telegrafenberg, 14473 Potsdam, GERMANY

5 Department of Earth Sciences, Cambridge University, Cambridge CB3 OEZ, ENGLAND

6 School of Marine Sciences, University of Haifa, Haifa 31905, ISRAEL

7 Institute of Geosciences, Christian Albrechts University, Kiel, GERMANY

* For correspondence, email: sklemp@stanford.edu

Since 1992, project INDEPTH (International Deep Profiling of Tibet and the Himalaya) geoscientists from Chinese, American, British, German, and Canadian institutions have collaborated to collect high-quality seismic, MT, and geologic data along a roughly north-south transect from the Himalaya to northern Tibet. The current field effort from 2007-2009, INDEPTH IV, targets the NE margin of the plateau, with goals of testing models of subduction (relict and current) near the Kunlun and Jinsha sutures and probing the deep geometry of key features such as the Kunlun and Altyn Tagh Faults. Our new datasets are intended to shed light on the possible existence of a lower-crustal flow channel beneath northern Tibet, analogous to the weak (and flowing?) lower crust evidenced by INDEPTH observations of mid-crustal low seismic velocities, seismic bright spots and high electrical conductivities (Nelson et al. 1996) in southern Tibet. INDEPTH IV further aims to evaluate the possible subduction of Asian crust from the north beneath the Kunlun suture (Kind et al. 2002) and to probe whether the Kunlun and Jinsha sutures act as crustal-scale faults.

\section{Active seismic experiment, summer 2007}

The INDEPTH IV active-source seismic experiment spans $270 \mathrm{~km}$ from the Qaidam Basin (Figure 1), across the North Kunlun Thrusts, the Kunlun Mountains, the North and South Kunlun Faults onto the Tibetan Plateau. The recording spread consists of four elements: 1) a wide-angle deployment of 295 IRIS PASSCAL Texan seismometers at $650 \mathrm{~m}$ spacing, 2) a nearvertical deployment of 655 Texans at $100 \mathrm{~m}$ spacing, 3) an adjacent deployment of a 1000-channel Sercel cabled spread with $50 \mathrm{~m}$ geophone spacing, and 4) an overlapping three-component array (48 Geophysical Instrument Pool Potsdam and SEIS-UK shortperiod and broadband instruments at $5-6 \mathrm{~km}$ spacing). Sources included five large shots (each 1000-2000 kg explosives) roughly evenly spaced along the profile, augmented by $\sim 110$ small shots (each $\sim 60-80 \mathrm{~kg}$ ) nominally spaced at $1 \mathrm{~km}$ in the central part of the profile.

We are using two-dimensional ray-tracing to model basin and basement refractions, and lower-crustal and Moho reflections to determine the crustal velocity structure. The preliminary model compiled incorporates a southward-thinning low-velocity Qaidam
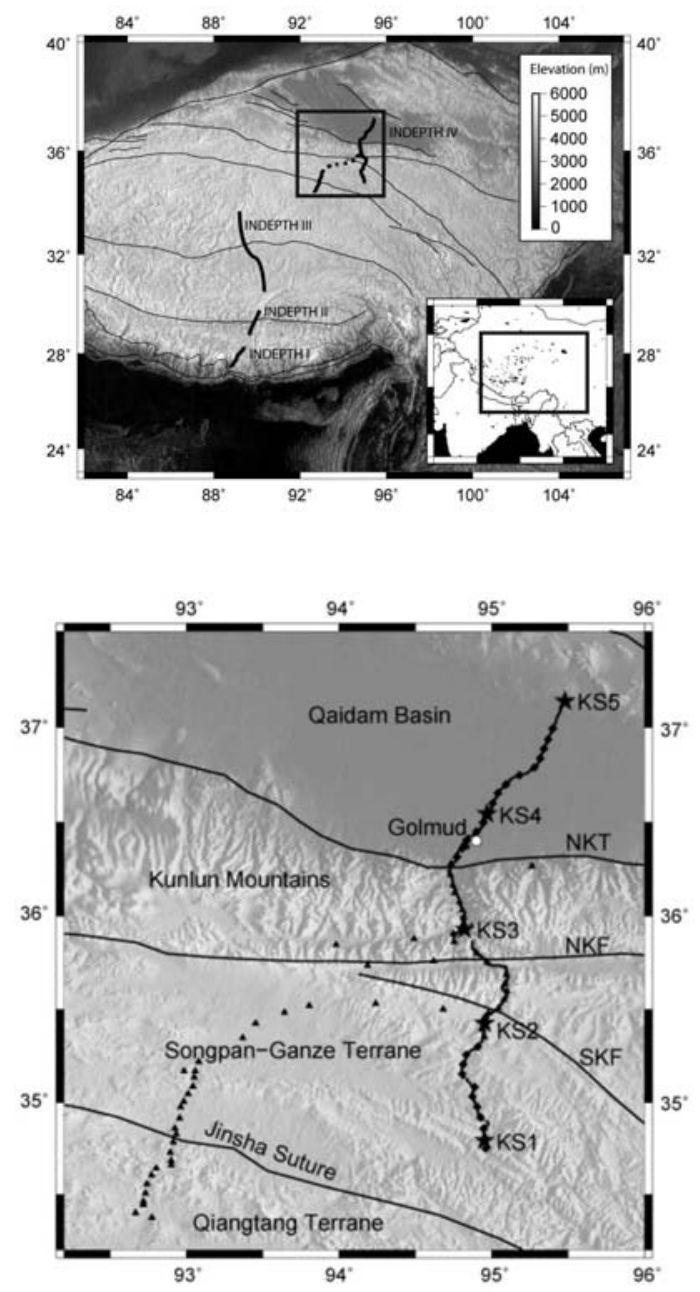

FIGURE 1. (a) Locations of INDEPTH I-IV transects spanning Tibetan Plateau. (b) Topographic map of northeast Tibet showing the locations of INDEPTH IV Texan and Sercel (continuous line of black dots) receivers, three-component short-period (diamonds) and broadband instruments (triangles), and small (circles) and large shots (stars). 
basin, unusually low crustal velocities of $6 \mathrm{~km} / \mathrm{s}$ compatible with older controlled-source observations further south and east in Tibet (e.g. Klemperer 2006), lower-crustal reflectors beneath the Plateau, and Moho depths of 50-55 km beneath the Qaidam Basin in the north. Near-vertical data from the small shots contains unusually strong s-wave arrivals as well as fault-plane reflections: reflectors at about 6 seconds beneath the Kunlun front range that we interpret as décollement horizons of the North Kunlun Thrusts.

Passive seismic experiment, 2007-2009

The passive seismic effort is cored by dense, linear broadband seismic arrays (59 stations at $\sim 5 \mathrm{~km}$ spacing) deployed across the Jinsha and Kunlun sutures. Depth-domain teleseismic receiver-function processing from these arrays should allow detailed mapping of the Moho, the base of the lithosphere, and possibly subducted elements of Asia. This high-resolution passive profiling is complemented by a large areal array simultaneously deployed across NE Tibet by the ASCENT (Array Seismology Collaborative Experiments in Northeastern Tibet) consortium. Data from these passive deployments is scheduled for retrieval in summer 2008.
Other studies: Geology, thermochronology \& magnetotellurics INDEPTH Sino-US field parties will investigate shortening and strike-slip deformation near the seismic transects in 2008, using thermochronologic and stratigraphic studies to investigate timing of shortening and total offset on different strands of the Kunlun fault. MT surveys are planned for 2009 across the Kunlun and Altyn Tagh Faults. These new data will augment the INDEPTH III profile, which showed that the middle crust is conductive as far north as the Kunlun Fault, although with less extreme conductivity values than in southern Tibet (Wei et al. 2001).

\section{References}

Kind R and 10 others. 2002. Seismic images of crust and upper mantle beneath Tibet: Evidence for Eurasian plate subduction. Science 298: 1219-1221

Klemperer SL. 2006. Crustal flow in Tibet: geophysical evidence for the physical state of Tibetan lithosphere, and inferred patterns of active flow. In: RD Law, MP Searle and L Godin, eds., Channel flow, ductile extrusion and exhumation in continental collision zones, Geological Society London Special Publication 268: 39-70

Nelson KD and 28 others. 1996. Partially molten middle crust beneath southern Tibet; synthesis of Project INDEPTH results. Science 274: 1684-1688

Wei $\mathrm{W}$ and 14 others. 2001. Widespread fluids in the Tibetan crust. Science 292: 716-718 